\title{
Improving outcomes for women after coronary artery bypass grafting: A case for prevention
}

\author{
Suzanne Oparil, MD
}

\begin{abstract}
Editorial Note: The gender initiative, a provocative series addressing gender differences in the surgical treatment of cardiac, vascular, and thoracic disease, continues with editorials addressing long-term outcomes of coronary artery surgery in women. Suzanne Oparil, MD, a cardiologist renowned for clinical and laboratory studies of women with cardiovascular disease, provides an excellent overview. Viola Vaccarino, MD, $\mathrm{PhD}$, and Colleen Koch, MD, address specific issues involving cardiac rehabilitation, quality of life, relief of symptoms, and long-term survival after cardiac surgery. The series continues next month with editorials addressing valvular heart disease in women.
\end{abstract}

Nancy A. Nussmeier, MD Texas Heart Institute

See related articles on pages 1707, 2032, and 2044.

\footnotetext{
From the Division of Cardiovacular Disease, Vascular Biology and Hypertension Program, University of Alabama at Birmingham, Birmingham, Ala.

Received for publication Sept 9, 2003; accepted for publication Oct 7, 2003.

Address for reprints: Suzanne Oparil, MD, Division of Cardiovacular Disease, Vascular Biology and Hypertension Program, University of Alabama at Birmingham, 703 19th St S, ZRB 1034, Birmingham, AL 35294-0007 (E-mail: soparil@uab.edu).

J Thorac Cardiovasc Surg 2003;126:1704-6

Copyright $\odot 2003$ by The American Association for Thoracic Surgery

$0022-5223 / 2003 \$ 30.00+0$

doi:10.1016/j.jtcvs.2003.10.008
}

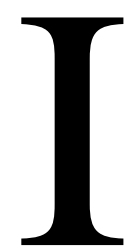

$\mathrm{n}$ this issue of the Journal,Vaccarino and $\mathrm{Koch}^{1}$ and Koch and associates ${ }^{2,3}$ come to grips with the knotty and contentious problem of why women have poorer outcomes than men after coronary artery bypass grafting (CABG). They use a database of 15,597 patients, including 3596 women, who underwent isolated CABG surgery at a single institution between 1993 and 2002 to address the question: "Is female gender a marker or a cause of increased risk of poor outcomes after coronary revascularization?" They observe an increased burden of cardiovascular disease risk factors and comorbid conditions, including hypertension, insulin-treated diabetes, heart failure, renal disease, peripheral vascular disease, and elevated low-density lipoprotein cholesterol and triglyceride levels, in women compared with men. Further, women had a more unstable presentation, including a higher prevalence of unstable angina, preoperative intraaortic balloon pump usage, and emergency surgery, compared with men. When propensity modeling techniques were used, only $26 \%$ of women could be matched on propensity scores with men because of the greater prevalence of risk factors and comorbidities among the women. While unadjusted postoperative morbidity and mortality outcomes were worse for women than for men overall, in well-matched patients, female gender was not a risk factor for in-hospital mortality and had minimal impact on postoperative morbidity.

The authors go on to discuss gender disparities in the long-term outcomes of CABG surgery, which include less relief of angina, more dyspnea, and lower functional status in women, without a reduction in survival. They point out an encouraging trend toward improved CABG outcomes in women, which they relate to technical advancements in surgical and myocardial protection techniques. The cardiovascular surgeons and their colleagues in anesthesiology deserve kudos for the major advances that they have made in this area. To achieve further gains in CABG outcomes for women, however, it is apparent that more needs to be done to facilitate the earlier diagnosis of clinically important coronary artery disease and related comorbid conditions in women. This approach should improve their cardiovascular risk profiles at the time of presentation for surgery, as well as their perioperative and postoperative outcomes. Even more important, aggressive strategies of lifestyle modification and cardiovascular risk factor reduction are urgently needed to reduce both the risk of CABG surgery and the need for the procedure in older women.

Effective methods for reducing cardiovascular risk by both lifestyle modification and pharmacologic means are clearly available, but there is evidence that these are underused in the very women who are at highest risk for cardiovascular disease and therefore become candidates for CABG surgery. ${ }^{4}$ For example, hypertension, the most common modifiable cardiovascular risk factor in women, is clearly inadequately managed in older women. The majority of women over age 65 years in the United States are hypertensive, and the prevalence of hypertension tracks closely with the prevalence of cardiovascular disease..$^{5}$ Abundant clinical trial evidence indicates that antihypertensive therapy is highly effective in preventing target organ damage, including heart attack, heart failure, and stroke, in women, as well as in men. ${ }^{6,7}$ Nevertheless, as shown in data from the Women's Health Initiative (WHI), hypertension is undertreated and inadequately controlled in women, particularly in high-risk elderly women. ${ }^{8}$ In the WHI cohort, blood pressure control rates were 
inversely related to age, declining from $41 \%$ in women in their 50 s to $29 \%$ in those older than 70 years, despite similar rates of antihypertensive drug treatment in the three decades. The majority of treated hypertensive women received only a single drug, an approach that has been repeatedly shown to be ineffective in controlling blood pressure, particularly in older, high-risk patients. ${ }^{9}$ WHI data are further revealing that hypertensive women had a constellation of risk factors, including overweight and sedentary lifestyle, that are susceptible to prevention and treatment by lifestyle modification.

Thresholds for instituting antihypertensive treatment, blood pressure goals, and choices of antihypertensive drugs are generally the same for women as for men. ${ }^{9}$ Lifestyle modification is clearly indicated in women with clinical hypertension or with blood pressure in the "prehypertensive" range because of its potential for preventing the progression to higher blood pressures and cardiovascular disease outcomes and for increasing the efficacy of pharmacologic treatment. Of the lifestyle interventions, weight loss and aerobic exercise are the most efficacious in reducing blood pressure and related cardiovascular disease risks such as dyslipidemia.

Similar to blood pressure, lipid levels are strong predictors of risk for coronary heart disease in women, who have an age-dependent unfavorable trend in lipid levels. Further, high-risk women derive similar or greater benefit than men from treatment with 3-hydroxy-3-methylglutaryl coenzyme A reductase inhibitors (statins). ${ }^{10-12}$ Accordingly, it is important to assess lipid levels and global cardiovascular risk and consider instituting both lifestyle modification and pharmacologic therapy for dyslipidemia in all women at menopause. A combination of prudent diet and exercise can improve levels of triglycerides and high- and low-density lipoprotein cholesterol. ${ }^{13}$ Detailed guidelines for thresholds and goals for pharmacologic treatment are published in the Third Report of the Expert Panel on Detection, Evaluation and Treatment of High Blood Cholesterol in Adults (Adult Treatment Panel III or ATP III). ${ }^{14}$ Although treatment recommendations are generally similar for women and men, some gender-specific issues play a role in the evaluation and management of dyslipidemia in women. For example, triglyceride levels are more powerful predictors of coronary heart disease risk in women than men and require particularly aggressive treatment.

Type 2 diabetes mellitus is a particularly powerful cardiovascular risk factor in women, equivalent to a history of myocardial infarction in predicting future coronary events. The Nurses' Health Study identified a 3-fold to 7-fold increase in cardiovascular events in women with type 2 diabetes compared with nondiabetic women.$^{15}$ The presence of diabetes is also associated with less favorable outcomes of percutaneous coronary revascularization, ${ }^{16}$ and
CABG is the preferred therapy in diabetic patients when invasive management is required. Accordingly, optimal diabetes management is a particularly critical component of efforts to improve outcomes in women undergoing CABG surgery. Women with diabetes should be managed with aggressive risk factor modification emphasizing weight control and physical activity, as well as use of pharmacologic therapy to achieve glucose control (goal hemoglobin A1C $<7 \%$ ), reduction of blood pressure to less than $130 / 80 \mathrm{~mm}$ $\mathrm{Hg}$, and reduction of low-density lipoprotein cholesterol to less than $100 \mathrm{mg} / \mathrm{dL}$ and non-high-density lipoprotein cholesterol to less than $130 \mathrm{mg} / \mathrm{dL}$.

Clearly, the incisive analysis of Koch and colleagues reveals that the poorer outcomes observed for women undergoing CABG surgery are not inevitable results of female gender. Rather, they result from a burden of comorbid conditions and modifiable risk factors that could be relieved by greater attention to lifestyle modification and more aggressive management of critical comorbid conditions, particularly diabetes, earlier in life. The hope for the future is that improved lifestyles and more diligent medical management may even the propensity scores and obliterate the gender disadvantage of older women undergoing CABG.

\section{References}

1. Vaccarino V, Koch GC. Long-term benefits of coronary bypass surgery: are the gains for women less than for men? J Thorac Cardiovasc Surg. 2003;126:1707-11.

2. Koch CG, Khandwala F, Nussmeier N, Blackstone EH. Gender and outcomes after coronary artery bypass grafting: a propensity-matched comparison. J Thorac Cardiovasc Surg. 2003;126:2032-43.

3. Koch CG, Khandwala F, Nussmeier N, Blackstone H. Gender profiling in coronary artery bypass grafting. J Thorac Cardiovasc Surg. 2003; 126:2044-51.

4. Miller AP, Bouchard P, Oparil S. Preventing CVD in women: are there gender-related differences with therapeutic implications? In: Egan BM, Basile JN, Lackland DT, editors. Hot topics in hypertension: a trip with the experts. Philadelphia: Hanley \& Belfus; 2003. p. 379-97.

5. American Heart Association. 2002 Heart and stroke statistical update. Dallas: American Heart Association; 2001.

6. Gueyffier F, Boutitie F, Biossel J-P, Pocock S, Coope J, Cutler J, et al. Effect of antihypertensive drug treatment on cardiovascular outcomes in women and men: a meta-analysis of individual patient data from randomized, controlled trials. The INDANA Investigators. Ann Intern Med. 1997; 126:761-767.

7. Calhoun DA, Oparil S. Gender and blood pressure. In: Izzo JL, Black HR, editors. Hypertension primer. 3rd ed. Baltimore: Lippincott, Williams \& Wilkins; 2003. p:253-7.

8. Wassertheil-Smoller S, Anderson G, Psaty BM, Black HR, Manson J, Wong $\mathrm{N}$, et al. Hypertension and its treatment in postmenopausal women: baseline data from the Women's Health Initiative. Hypertension. 2000;36:780-9.

9. Chobanian AV, Bakris GL, Black HR, Cushman WC, Green LA, Izzo JL Jr, et al. The Seventh Report of the Joint National Committee on Prevention, Detection, Evaluation, and Treatment of High Blood Pressure: the JNC 7 report. JAMA. 2003;289:2560-72.

10. Pedersen TR, Kjekshus J, Berg K, et al, on behalf of the Scandanavian Simvastatin Survival Group. Randomized trial of cholesterol lowering in 4444 patients with coronary heart disease: the Scandanavian Simvastatin Survival Study (4S). Lancet. 1994;344:1383-9. 
11. Lewis SJ, Sacks FM, Mitchell JS, East C, Glasser S, Kell S, et al. Effect of pravastatin on cardiovascular events in women after myocardial infarction. J Am Coll Cardiol. 1998;32:140-6.

12. Collins R, Armitage J, Parish S, et al, for the Heart Protection Study Collaborative Group. MRC/BHF Heart Protection Study of cholesterol lowering with simvastatin in 20,536 high-risk individuals: a randomized placebo-controlled trial. Lancet. 2002;360:7-22.

13. Kraus WE, Houmard JA, Dusha BD, Knetzger KJ, Wharton MB, McCartney JS, et al. Effects of the amount and intensity of exercise on plasma lipoproteins. N Engl J Med. 2002;347:1483-92.

14. Grundy SM, Becker D, Clark LT, et al, for the Expert Panel on Detection, Evaluation, and Treatment of High Blood Cholesterol in
Adults. Executive summary of the Third Report of the National Cholesterol Education Program (NCEP) Expert Panel on Detection, Evaluation, and Treatment of High Blood Cholesterol in Adults (Adult Treatment Panel III). JAMA. 2001;285:2486-97.

15. Manson JE, Colditz GA, Stampfer MJ, Willett WC, Krolewski AS, Rosner B, et al. A prospective study of maturity-onset diabetes mellitus and risk of coronary heart disease and stroke in women. Arch Intern Med. 1991;151:1141-7.

16. Kip KE, Faxon DP, Detre KM, Yeh W, Kelsey SF, Currier JW. Coronary angioplasty in diabetic patients: the National Heart, Lung, and Blood Institute Percutaneous Transluminal Coronary Angioplasty Registry. Circulation. 1996;94:1818-25.

Access to The Journal of Thoracic and Cardiovascular Surgery Online is reserved for print subscribers!

Full-text access to The Journal of Thoracic and Cardiovascular Surgery Online is available for all print subscribers. To activate your individual online subscription, please visit The Journal of Thoracic and Cardiovascular Surgery Online, point your browser to http://www.mosby.com/itcvs, follow the prompts to activate your online access, and follow the instructions. To activate your account, you will need your subscriber account number, which you can find on your mailing label (note: the number of digits in your subscriber account number varies from 6 to 10). See the example below in which the subscriber account number has been circled:

\section{Sample mailing label}

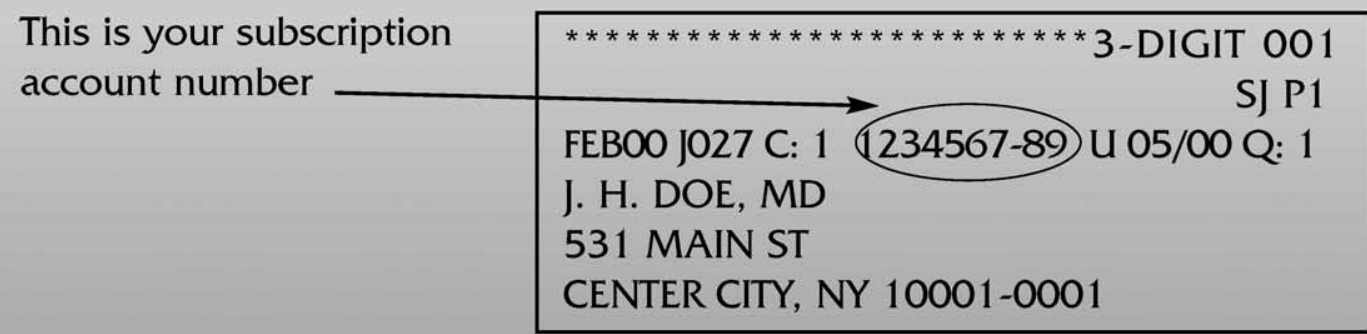

Personal subscriptions to The Journal of Thoracic and Cardiovascular Surgery Online are for individual use only and may not be transferred. Use of The Journal of Thoracic and Cardiovascular Surgery Online is subject to agreement to the terms and conditions as indicated online. 